\title{
Prophylactic Robotic-assisted Laparoscopic Radical Prostatectomy for Preoperative Suspicion of Prostate Cancer: Experience with 55 Cases
}

\author{
YEN-CHUAN OU ${ }^{1,2,5}$, WEI-CHUN WENG ${ }^{6}$, KUANGH-SI CHANG $^{2}$, CHENG-EN MEI $^{1,5}$, \\ CHUN KUANG YANG ${ }^{1,5}$, SIU-WAN HUNG ${ }^{3,5}$, JOHN WANG ${ }^{4,5}$ and MIN-CHE TUNG ${ }^{6}$ \\ ${ }^{1}$ Division of Urology, Department of Surgery, and Departments of ${ }^{2}$ Research, ${ }^{3}$ Radiation, and \\ ${ }^{4}$ Pathology, Taichung Veterans General Hospital, Taichung, Taiwan, R.O.C.; \\ ${ }^{5}$ School of Medicine, National Yang-Ming University, Taipei, Taiwan, R.O.C.; \\ ${ }^{6}$ Division of Urology, Department of Surgery, Tungs' Taichung Metro Harbor Hospital, Taichung, Taiwan, R.O.C.
}

\begin{abstract}
Background/Aim: Expanded indications are not yet reported for robotic-assisted laparoscopic radical prostatectomy $(R A R P)$ performed by experienced surgeons for patients with preoperative suspicion of prostate cancer. We report our experience with 55 cases of prophylactic RARP for preoperative suspicion of prostate cancer, including postoperative pathological characteristics and outcomes. Patients and Methods: This retrospective study reviewed data of a subset of 55 consecutive patients among 1,060 patients who underwent RARP for preoperative suspicion of prostate cancer. Pathological characteristics and outcomes of patients with suspected prostate cancer were analyzed and preoperative, intraoperative and postoperative parameters were compared between three groups. Patients were stratified by final pathology reports of RARP specimens: Group I: Prostate cancer, $N=22$ (40\%); group II: abnormal (prostate intraepithelial neoplasia; atypical small acinar proliferation), $N=18$ (32.7\%); and group III: benign (nodular hyperplasia or inflammation), $N=15$ (27.3\%). Results: Mean preoperative prostate-specific antigen (PSA) was $16.04 \pm 2.21 \mathrm{ng} / \mathrm{ml}$. Twentytwo patients with adenocarcinoma had pathology stage pT2a/T2b/T2c/T3a/T3b (6/7/2/6/1 patients, respectively), with positive surgical margins in $18.2 \%$ (4/22). Preoperative incidence of PSA velocity $>0.75 \mathrm{ng} / \mathrm{ml} / \mathrm{yr}$ was significantly higher in group I than in groups II and III (81.8\% vs. 38.9\% vs. $33.3 \%, p=0.004)$. Predictive parameters of prostate cancer showed that PSA velocity (>0.75 vs. $\leq 0.75 \mathrm{ng} / \mathrm{ml} / \mathrm{yr}$ ) had crude
\end{abstract}

Correspondence to: Yen-Chuan Ou, MD, Ph.D., 1650 Taiwan Boulevard Sect. 4, Taichung, Taiwan 40705, R.O.C. Tel: +886 423741215, Fax: +886 423593160, e-mail: ycou228@gmail.com

Key Words: Laparoscopy, suspicion of prostate cancer, radical prostatectomy, robotics. odds ratio of 9.0 for group I vs. group III, $p=0.005$. Posteperatively, statistically significant improvements were found in uroflow rate, post-voiding residual urine and symptom scores (all $p<0.0001$ ). Conclusion: Prophylactic RARP with bilateral neurovascular bundle preservation performed by experienced surgeons is a safe and viable option for preoperative suspicion of prostate cancer.

Open radical prostatectomy (ORP) has been the gold standard of surgical treatment for localized prostate cancer (PC) since $1982(1,2)$. This trend included minimally invasive surgery such as laparoscopic radical prostatectomy and robotic-assisted laparoscopic radical prostatectomy (RARP) (2). RARP is rapidly gaining acceptance in the urology community for treating localized PC, and is applied in about $85 \%$ of prostatectomies carried out in the USA (3). RARP offers excellent functional recovery, lasting oncologic control and the best safety profile compared to other methods (4-7). The 1-year continence rate and 1.5-year potency rate were $95 \%$ or more in high-volume centers $(4,5)$. Actuarial cancer-specific survival rates at 10 years is $98.8 \%$ (6). Coelho et al. reported a $3.3 \%$ decrease in complication rates for RARP after gaining experience with the procedure (8). Surgeons at the Vattikuti Urology Institute report that in their experience, RARP is inching towards the gold standard (5).

A subset of patients with suspicious PC or abnormal prostate biopsy [prostate intraepithelial neoplasia (PIN); atypical small acinar proliferation (ASAP)] raises concern about the possible presence of malignant disease, and men with lower urinary tract symptoms and elevated prostatespecific antigen (PSA) results are especially afraid of having PC $(9,10)$. High levels of distress and anxiety remained elevated immediately after negative biopsy results and up to 12 weeks later (11). Brausi et al. reported that 25 patients underwent ORP after diagnosis of ASAP, and all patients had 
Table I. Comparison of preoperative and postoperative pathology in robotic-assisted radical prostatectomy.

\begin{tabular}{|c|c|c|c|c|c|}
\hline Preoperative diagnosis & $\operatorname{ASAP}(n=1)$ & $\operatorname{PIN}(\mathrm{n}=5)^{\mathrm{a}}$ & Benign $(n=36)$ & No biopsy $(\mathrm{n}=13)$ & $\mathrm{N}=55$ \\
\hline \multicolumn{6}{|l|}{ Postoperative diagnosis } \\
\hline Adenocarcinoma & 1 & 2 & 14 & 5 & 22 \\
\hline ASAP & 0 & 0 & 5 & 0 & 5 \\
\hline PIN & 0 & 2 & 7 & 4 & $13^{\mathrm{b}}$ \\
\hline Benign & 0 & 1 & 10 & 4 & 15 \\
\hline
\end{tabular}

PIN: Prostate intraepithelial neoplasia; ASAP: atypical small acinar proliferation, Benign [nodular hyperplasia (NH) or inflammation]. ${ }^{\text {LLow-grade }}$ (LG) PIN ( $n=2$ ), high-grade (HG) PIN ( $n=3$ ) and one LG PIN shown as NH postoperatively; bL PIN ( $n=4)$, HG PIN ( $n=9$ ).

a final pathological diagnosis of adenocarcinoma (12). Immediate radical prostatectomy (RP) may be the treatment of choice in young patients with ASAP (12). Likewise, RP is sometimes suggested for high-grade PIN (13). Recently, robotic-assisted simple prostatectomy (RASP) has also been performed for lower urinary tract symptoms (LUTS) and benign prostatic enlargement (14).

Expanded indications have not yet been reported for RARP performed by experienced surgeons for patients with preoperative suspicion of PC. This study aimed to report our experience with 55 cases of prophylactic RARP performed for preoperative suspicion of PC, including postoperative pathological characteristics and outcomes.

\section{Patients and Methods}

Study design and sample. We retrospectively reviewed data of single-surgeon ( $\mathrm{YC} \mathrm{Ou}$ ) experience with 1,060 patients who underwent RARP between December 2005 and July 2015. Preoperatively, 1005 patients were diagnosed with PC and 55 patients with suspicion of PC were enrolled in this study. Three patients were medical doctors. The Institutional Review Board of our hospital reviewed and approved the study protocol (number: CE 15215B). All enrolled patients provided signed informed consent.

A total of 365 RARP had been performed previously, and the first case of prophylactic RARP with bilateral neurovascular bundle (NVB) preservation was also performed in February 2012 for preoperative suspicion of PC. Transrectal ultrasound (TRUS)-guided prostate needle biopsy was carried out for all patients. Patients were followed for at least 6 months after the initial visit, including repeat PSA, repeat biopsy, magnetic resonance imaging (MRI) and a period of time for patients to consider their options. Patients and their families were invited to attend a group education course moderated by the first author, and the patients were informed about RARP complications, including postoperative recovery of sexual potency and orgasm without ejaculation fluid. Patients understood well that the final pathology may reveal benign lesions, that PSA may be elevated and that abnormal digital rectal examination (DRE) of prostate and suspicious prostate lesions on 3-T MRI were not definitive of PC.

Surgical parameters. Patients' recorded preoperative demographic and clinical characteristics included age, body mass index (BMI), American Society of Anesthesiologists anesthetic/surgical risks class
(ASA), PSA level, prostate volume, PSA density, symptoms scores and quality of life (QOL) scores, history of acute urinary retention, abnormal DRE of prostate, suspicious prostate lesion at 3-T multiparametric MRI $(15,16)$. Thirteen patients, including two medical doctors, were not willing to undergo TRUS biopsy. Fortyone patients volunteered to undergo MRI and paid charges by themselves. MRI interpretation with the Prostate Imaging Reporting and Data System (PI-RADS) classification was adopted $(17,18)$. We performed RARP with intra- or inter-fascial neurovascular bundle preservation, as previously described $(7,19,20)$.

Parameters recorded for each surgery included: surgeon's console time, vesicourethral anastomosis time, estimated blood loss, transfusion rate, specimen volume, and complication rate. Specimens were fixed, coated with Indian ink and cut into systematic stepwise sections at $3 \mathrm{~mm}$ intervals (7). The tumor volume, tumor percentage, Gleason score, pathologic stage, positive surgical margin rate, perineural invasion, angiolymphatic invasion and node-positive rate were recorded.

Patient follow-up at 6 weeks after RARP included evaluation of uroflow rate, symptom score, QOL score and PSA determination. Continence was defined as having no pad use. The mean preoperative PSA was $16.04 \pm 2.21 \mathrm{ng} / \mathrm{ml}$. The final pathology report from RARP specimens disclosed adenocarcinoma in 22 out of 55 cases. Patients were stratified into three groups as follows: Group I: PC, $\mathrm{N}=22$ (40\%); group II: abnormal (PIN, ASAP), $\mathrm{N}=18$ $(32.7 \%)$; group III: benign (nodular hyperplasia or inflammation), $\mathrm{N}=15(27.3 \%)$.

Statistical analysis. All data are expressed as the mean \pm SD. All statistical calculations were performed using SPSS 12.0 for Windows (SPSS, Inc., Chicago, IL, USA). Statistical analysis was performed using Kruskal-Wallis test, $\mathrm{X}^{2}$ test, Mann-Whitney $U$-test and multiple logistic regression as appropriate. A $p$-value less than 0.05 was considered statistically significant.

\section{Results}

Table I shows comparisons of preoperative and postoperative pathology after RARP in the 55 patients with suspicion of PC. Forty-two patients underwent TRUS-guided prostate needle biopsy 1-4 times. ASAP or PIN was noted in six patients preoperatively. Postoperatively, adenocarcinoma was found in three patients, PIN in two and benign lesion in one. Final pathology reports for 36 patients with benign nodular 
Ou et al: Prophylactic Robotic-assisted Radical Prostatectomy for Suspicion of Prostate Cancer

Table II. Preoperative clinical characteristics of robotic-assisted radical prostatectomy for suspicion of prostate cancer.

\begin{tabular}{|c|c|c|c|c|c|}
\hline Clinical data & $\begin{array}{c}\text { Group I: Prostate cancer, } \\
\qquad \mathrm{N}=22(40 \%)\end{array}$ & $\begin{array}{l}\text { Group II: Abnormal*, } \\
\mathrm{N}=18(32.7 \%)\end{array}$ & $\begin{array}{l}\text { Group III: Benign**, } \\
\mathrm{N}=15(27.3 \%)\end{array}$ & $p$-Value & Total $(55 / 55=100 \%)$ \\
\hline Age (years) mean \pm SEM & $66.27 \pm 1.55$ & $63.94 \pm 1.83$ & $61.27 \pm 1.19$ & $0.130^{\mathrm{a}}$ & $64.15 \pm 0.93$ \\
\hline $\mathrm{BMI}$, mean $\pm \mathrm{SEM} \mathrm{kg} / \mathrm{m}^{2}$ & $24.23 \pm 0.62$ & $25.14 \pm 0.85$ & $25.70 \pm 0.76$ & $0.264^{\mathrm{a}}$ & $24.93 \pm 0.43$ \\
\hline ASA score I/II/III & $3 / 18 / 1$ & $1 / 15 / 2$ & $4 / 10 / 1$ & $0.481^{\mathrm{b}}$ & $8 / 43 / 4$ \\
\hline PSA $(\mathrm{ng} / \mathrm{ml})$, mean \pm SEM & $15.26 \pm 2.32$ & $19.42 \pm 5.42$ & $13.14 \pm 3.55$ & $0.454^{\mathrm{a}}$ & $16.04 \pm 2.21$ \\
\hline Prostate volume $\left(\mathrm{cm}^{3}\right)$, mean \pm SEM & $58.18 \pm 5.79$ & $60.89 \pm 5.74$ & $61.47 \pm 7.01$ & $0.801^{\mathrm{a}}$ & $59.96 \pm 3.48$ \\
\hline PSA density, mean \pm SEM & $0.33 \pm 0.07$ & $0.33 \pm 0.08$ & $0.28 \pm 0.07$ & $0.807^{\mathrm{a}}$ & $0.30 \pm 0.04$ \\
\hline PSA velocity $>0.75 \mathrm{ng} / \mathrm{ml} / \mathrm{yr}$ & $81.8 \%(18 / 22)$ & $38.9 \%(7 / 18)$ & $33.3 \%(5 / 15)$ & $0.004^{b}$ & $56.4 \%(31 / 55)$ \\
\hline Symptom score, mean \pm SEM & $18.09 \pm 1.68$ & $20.22 \pm 1.71$ & $21.20 \pm 1.84$ & $0.417^{\mathrm{a}}$ & $19.64 \pm 1.01$ \\
\hline AUR (yes/no) & $4 / 18$ & $5 / 13$ & $4 / 11$ & $0.737^{\mathrm{b}}$ & $13 / 42$ \\
\hline No. of biopsies, mean \pm SEM & $1.41 \pm 0.22$ & $0.94 \pm 0.15$ & $0.93 \pm 1.82$ & $0.248^{\mathrm{a}}$ & $1.13 \pm 0.12$ \\
\hline \multicolumn{6}{|l|}{ Biopsy pathology, PIN or } \\
\hline ASAP/NH or inflammation & $3 / 14$ & $2 / 12$ & $1 / 10$ & $0.819^{\mathrm{b}}$ & $6 / 36$ \\
\hline $\begin{array}{l}\text { Digital rectal examination, } \\
\text { normal/abnormal }\end{array}$ & $5 / 17$ & $4 / 14$ & $4 / 11$ & $0.948^{\mathrm{b}}$ & $13 / 42$ \\
\hline MRI (PI-RADS score) 2-3/4-5 & $5(29.4 \%) / 12(70.6 \%)$ & $6(42.9 \%) / 8(57.1 \%)$ & $6(60.0 \%) / 4(40.0 \%)$ & $0.295^{b}$ & $17(41.5 \%) / 24(58.5 \%)$ \\
\hline Day of Continence & $13.14 \pm 2.40$ & $9.72 \pm 1.79$ & $9.40 \pm 2.43$ & $0.577^{\mathrm{a}}$ & $11.00 \pm 1.30$ \\
\hline
\end{tabular}

*Abnormal: Prostate intraepithelial neoplasia, atypical small acinar proliferation; **Benign: nodular hyperplasia or inflammation; BMI: body mass index; PSA: prostate-specific antigen; PSA density: PSA/prostate volume by transrectal sonography; ASA: American Society of Anesthesiologists anesthetic/surgical risks class; AUR: acute urinary retention; MRI: magnetic resonance image; PI-RADS: Prostate Imaging Reporting and Data System. ${ }^{a}$ By Kruskal-Wallis test; byChi-square test.

Table III. Operative parameters and complication rate of robotic-assisted radical prostatectomy.

\begin{tabular}{|c|c|c|c|c|c|}
\hline Factor & $\begin{array}{c}\text { Group I: Prostate cancer } \\
\qquad \mathrm{N}=22(40 \%)\end{array}$ & $\begin{array}{l}\text { Group II: Abnormal* } \\
\quad \mathrm{N}=18(32.7 \%)\end{array}$ & $\begin{array}{l}\text { Group III: Benign** } \\
\mathrm{N}=15(27.3 \%)\end{array}$ & $p$-Value & Total $(55 / 55=100)$ \\
\hline Console time (min), mean \pm SEM & $111.82 \pm 4.49$ & $115.17 \pm 6.21$ & $119.00 \pm 6.08$ & $0.663^{\mathrm{a}}$ & $114.87 \pm 3.14$ \\
\hline $\begin{array}{l}\text { Vesicourethral anastomosis } \\
\text { time (min) mean }+ \text { SEM }\end{array}$ & & & & & \\
\hline $\begin{array}{l}\text { time }(\min ) \text { mean } \pm \text { SEM } \\
\text { Blood loss }(\mathrm{ml}), \text { mean } \pm \text { SEM }\end{array}$ & $\begin{array}{c}21.77 \pm 1.45 \\
78.86 \pm 12.47\end{array}$ & $\begin{array}{c}21.64 \pm 1.14 \\
95.83 \pm 19.98\end{array}$ & $\begin{array}{c}21.80 \pm 1.47 \\
103.67 \pm 16.61\end{array}$ & $\begin{array}{l}0.906^{\mathrm{a}} \\
0.215^{\mathrm{a}}\end{array}$ & $\begin{array}{l}21.75 \pm 0.81 \\
91.18 \pm 9.32\end{array}$ \\
\hline Transfusion rate, $\mathrm{n}$ & 0 & 0 & 0 & & \\
\hline Complication rate, $\mathrm{n}(\%)$ & $2 / 22(9.1 \%)$ & $0 / 18(0 \%)$ & $0 / 15(0 \%)$ & $0.211^{\mathrm{b}}$ & $2 / 55(3.6 \%)^{* * *}$ \\
\hline Specimen volume $\left(\mathrm{cm}^{3}\right)$, mean \pm SEM & $61.89 \pm 5.74$ & $64.67 \pm 5.90$ & $66.63 \pm 7.18$ & $0.863^{\mathrm{a}}$ & $64.01 \pm 3.53$ \\
\hline
\end{tabular}

*Abnormal: Prostate intraepithelial neoplasia, atypical small acinar proliferation; **Benign: nodular hyperplasia or inflammation; ***Clavien I: Ileus $(n=1)$, intraoperative bladder injury with repair $(n=1)$. ${ }^{a}$ By Kruskal-Wallis test; byChi-square test.

hyperplasia and inflammation preoperatively revealed adenocarcinoma $(n=14)$, ASAP or PIN $(n=12)$, and benign lesions $(n=10)$. In 13 cases without prostate biopsy at patients' discretion, the final pathology also revealed adenocarcinoma $(n=5)$, ASAP or PIN $(n=4)$, and benign lesions $(n=4)$.

Preoperative clinical characteristics of RARP for suspicion of PC are shown in Table II. The incidence of PSA velocity $>0.75 \mathrm{ng} / \mathrm{ml} / \mathrm{yr}$ was significantly higher $(81.8 \%)$ in group I than in groups II $(38.9 \%)$ and III $(33.3 \%)(p=0.004)$. The incidence of PI-RADS score of 4-5 by MRI was higher in group I than in groups II and III $(70.6 \%, 57.1 \%$ and $40 \%$, respectively), but without significant differences $(p=0.295)$.
Operative parameters and complication rates of RARP are shown in Table III. More blood loss occurred in group III than in groups I and II, but without statistically significant differences. Two Clavien-Dindo I complications were noted, including transient postoperative ileus and intraoperative bladder injury with repair.

Table IV shows the final pathological characteristics of PC in 22 patients. Tumor volume ranged from 0.1 to $12 \mathrm{ml}$ with a mean of $3.0 \mathrm{ml}$. Tumor volume $\leq 1 \mathrm{ml}$ was found in eight patients. Pathology stages T2a/T2b/T2c/T3a/T3b were recorded as $6 / 7 / 2 / 6 / 1$. The positive surgical margin rate was $19 \%$ and angiolymphatic invasion was $4.5 \%$. 
Comparisons of preoperative and postoperative urinary function are shown in Table $\mathrm{V}$, including voided urine amount, and significantly increased maximal and mean uroflow rate after RARP. Post-voiding residual urine, symptoms scores and QOL scores were significantly reduced. The continence rate was $100 \%$. The time of return to continence ranged from day 0 to day 28 (mean: day 11) after removal of the urethral catheter.

Table VI displays assessment of preoperative predictive parameters for PC. Adjusted odds ratio of PSA velocity was 5.97 for PC (group I) versus benign histology (group III) $(p=0.029)$, indicating a significant difference. The crude odds ratio of MRI PI-RADS scores for PC (group I) versus benign histology (group III) was 3.60, without statistically significant differences.

\section{Discussion}

As far as we are aware, this study is the first to report results of prophylactic RARP for preoperative suspicion of PC with mean PSA $16.04 \pm 2.21 \mathrm{ng} / \mathrm{ml}$. The final pathological characteristics of 55 patients revealed that $40 \%$ of suspicious cases had PC and, of these, 91\% (20/22) had clinically significant cancer $(\geq 0.5 \mathrm{ml})$, as described previously (21). This is an extended indication of RARP from diagnosis of PC to only suspicion of PC. All patients had satisfactory outcomes after RARP.

TRUS-guided prostate needle biopsy is fundamental for PC diagnosis. However, the 30-day hospital re-admission rate after biopsy was $4.1 \%$, the majority (72\%) of which was due to infection (22). The overall 30-day mortality rate was $0.09 \%$ (22). This subset of patients with suspicious PC may undergo RASP. Pokorny et al. reported that 67 patients with LUTS underwent RASP, and $15 \%$ were diagnosed with PC at final pathology, while $30 \%$ had complications, including 9\% Clavien-Dindo grade III complications (14). In another multicenter study, complications of RASP were $16.6 \%$ (81/487), 2.4\% (12/487) of grade III-V (23).

Other options for patients with suspicion of PC include transurethral resection of the prostate (TURP). A nationwide population-based study in Taiwan from 2003 Taiwan National Health Insurance Research Database reported that 9,539 patients had undergone TURP, with in-hospital mortality rates of $2.37 \%, 1.97 \%$, and $1.16 \%$ in hospitals with low- (27 cases/yr), medium- (27-55 cases/yr), and highvolume $(>55$ cases/yr) urological group practice, respectively, (24). When PC is diagnosed after TURP, RP may still be needed later. In high-volume urological surgical practice, complication rates of RARP were reduced to $3 \%$ (8). In our earlier experience, the complication rate of RARP was $6.0 \%$ for cases $201-600,4.0 \%$ for cases $601-1000$, and with no mortality (25). The first case of RARP for a patient with suspicion of PC was case number 366 . This 54-year-old
Table IV. Pathological characteristics of prostate cancer after roboticassisted radical prostatectomy.

\begin{tabular}{lc}
\hline Factor & Number $(\mathrm{N}=22)$ \\
\hline Tumor volume, mean (range), & $3.0 \mathrm{ml}(0.1-12 \mathrm{ml})$ \\
Tumor percentage, mean (range) & $8.67 \%(0.5-65 \%)$ \\
Pathological stage T2a/T2b/T2c/T3a/T3b & $6 / 7 / 2 / 6 / 1$ \\
Gleason score 5/6/7/8 & $3 / 9 / 7 / 3$ \\
Positive surgical margin, n (\%) & $4 / 22(18.2 \%)$ \\
Perineural invasion, n (\%) & $5 / 22(22.7 \%)$ \\
Angiolymphatic invasion, n (\%) & $1 / 22(4.5 \%)$ \\
Node metastasis, n $(\%)$ & $0 / 22(0 \%)$ \\
\hline
\end{tabular}

Tumor volume $\leq 1 \mathrm{ml}$ in eight patients, $0.1 \mathrm{ml}$ in one, $0.3 \mathrm{ml}$ in one, $0.5 \mathrm{ml}$ in two, $0.6 \mathrm{ml}$ in one, $0.75 \mathrm{ml}$ in one, and $1 \mathrm{ml}$ in two.

Table V. Preoperative and postoperative urinary function in robotic assisted radical prostatectomy.

\begin{tabular}{lccc}
\hline Function & Preoperative & Postoperative & $p$-Value \\
\hline Voiding volume, ml & $164.11 \pm 8.99$ & $225.22 \pm 6.89$ & $<0.001$ \\
Maximum flow rate & $9.04 \pm 0.64$ & $21.39 \pm 0.63$ & $<0.001$ \\
Mean flow rate & $4.36 \pm 0.37$ & $11.98 \pm 0.51$ & $<0.001$ \\
Post-voiding residual urine, $\mathrm{ml}$ & $79.73 \pm 11.46$ & $7.53 \pm 1.09$ & $<0.001$ \\
Symptom score & $19.64 \pm 1.01$ & $3.11 \pm 0.17$ & $<0.001$ \\
QOL score & $3.82 \pm 0.14$ & $0.33 \pm 0.14$ & $<0.001$ \\
Continence rate & & $100 \%$ & \\
Day of continence & & $11.00 \pm 1.30$ & \\
\end{tabular}

Data are the mean \pm SEM. QOL: Quality of life. ${ }^{a}$ By Mann-Whitney $U$-test.

patient's PSA was $11.7 \mathrm{ng} / \mathrm{ml}$. He had experienced sepsis after the second TRUS prostate biopsy, and did not want to undergo another, insisting that he wanted RARP. The patient was also very afraid of the disease because five of his relatives and friends had died of PC. Performing RARP for patients with suspicion of PC is not a new robotic procedure, but it is an extended indication. Despite this, RARP is feasible and safe in high-volume urology surgical practice, and has certain medico-legal issues that justify the need for avoiding complications.

MRI is an excellent tool for detecting suspicious lesions. The tumor incidence of targeted multiparametric MRIultrasound image fusion-guided repeat biopsy was 19\%,65\% and $94 \%$ in those with 3, 4 and 5 PI-RADS scores, respectively (18). Salami et al. noted that higher levels of suspicion on MRI were significantly associated with PC detection with an area under the curve of 0.744 , compared with 0.653 for PSA level and 0.680 for PSA density (26). No targeted multiparametric MRI-ultrasound image fusionguided biopsy is performed at our hospital. Our data showed that $70.6 \%$ of the PC group had PI-RADS scores 4-5, with 
Ou et al: Prophylactic Robotic-assisted Radical Prostatectomy for Suspicion of Prostate Cancer

Table VI. Predictive parameters of prostate cancer before robotic-assisted radical prostatectomy: odds ratio for prostate cancer (group I) versus benign histology (group III).

\begin{tabular}{|c|c|c|c|c|c|c|}
\hline Preoperative parameter & Crude OR & $95 \% \mathrm{CI}$ & $p$-Value* & Adjusted OR & $95 \% \mathrm{CI}$ & $p$-Value* \\
\hline Age & 1.18 & $1.01-1.37$ & 0.034 & 1.12 & $0.95-1.32$ & 0.166 \\
\hline BMI & 0.84 & $0.66-1.06$ & 0.146 & & & \\
\hline PSA & 1.02 & $0.96-1.08$ & 0.596 & & & \\
\hline Prostate volume & 1.00 & $0.97-1.02$ & 0.711 & & & \\
\hline PSA density & 1.72 & $0.18-16.99$ & 0.642 & & & \\
\hline PSA velocity (>0.75 vs. $<0.75 \mathrm{ng} / \mathrm{ml} / \mathrm{yr}$ ) & 9.00 & $1.96-41.36$ & 0.005 & 5.97 & $1.21-29.59$ & 0.029 \\
\hline Symptom score & 0.95 & $0.86-1.04$ & 0.225 & & & \\
\hline AUR: $2 v s .1$ & 0.61 & $0.13-2.96$ & 0.540 & & & \\
\hline Biopsy: ASAP or PIN $v s$. benign & 2.14 & $0.19-23.72$ & 0.534 & & & \\
\hline Biopsy vs.no biopsy & 1.64 & $0.34-7.91$ & 0.540 & & & \\
\hline No. of biopsies: $>1$ vs. 0 or 1 & 2.77 & $0.60-12.71$ & 0.190 & & & \\
\hline Digital examination: abnormal vs.normal & 0.81 & $0.18-3.69$ & 0.784 & & & \\
\hline MRI PI-RADS score 4-5 vs. 2-3 & 3.60 & $0.70-18.56$ & 0.126 & & & \\
\hline
\end{tabular}

OR: Odds ratio; CI: confidence interval; BMI: body mass index; PIN: prostate intraepithelial neoplasia; ASAP: atypical small acinar proliferation; AUR: acute urinary retention, MRI: magnetic resonance image; PI-RADS: Prostate Imaging Reporting and Data System. *Multiple logistic regression.

no significantly higher result than the abnormal and benign prostate groups (Table II). However, the crude odds ratio of MRI PI-RADS score for PC (group I) compared with benign histology (group III) was $3.60(p=0.126)$, not statistically significant, which may be due to limited case numbers. As such, it is not a preoperative predictor for PC.

Data of the present study show that PSA velocity $>0.75 \mathrm{ng} / \mathrm{ml} / \mathrm{yr}$ is a good predictor of PC (Table VI). Loeb et al. presented a large PC screening study of 13,615 men, concluding that PSA velocity is useful for PC detection, with median PSA velocity of $0.6-0.7 \mathrm{ng} / \mathrm{ml} / \mathrm{yr}$ in patients with PC (27). Other investigators reported that PSA velocity was $>0.4 \mathrm{ng} / \mathrm{ml} /$ year twice in $40 \%$ of PC cases (28). Another study showed that a PSA velocity threshold of $0.75 \mathrm{ng} / \mathrm{mL} / \mathrm{yr}$ predicted which men with high-grade PIN would ultimately be diagnosed with PC ( $p=0.007)$ (29). However, in the present study, the incidence of PSA velocity $>0.75 \mathrm{ng} / \mathrm{ml} / \mathrm{yr}$ was similar (38.9\% versus $33.3 \%$ ) between the abnormal group (PIN or ASAP) and benign group (Table II).

Our cohort of 55 patients was classified by TRUS prostate biopsy results as having a precursor lesion (ASAP or PIN) in six patients and benign prostate in 36 patients; with no biopsy undertaken in 13 patients. Brausi et al. performed immediate RP in 25 out of 71 patients with ASAP, and all 25 patients underwent ORP, confirming the lesion pathologically as adenocarcinoma (12). Later, prostatic adenocarcinoma was diagnosed in 9 out of 23 patients $(39.1 \%)$ at repeated biopsies at between 6 to 12 months follow-up (12). These authors suggested that ORP was the treatment of choice for young patients with ASAP (12). Woderich et al. reported using ORP for high-grade PIN in one patient whose father had died of metastatic PC (13). Only 3 out of 55 patients in the present study had a family history of PC. High-grade PIN is the most likely precursor of PC and adenocarcinoma was identified in $35 \%$ of repeat biopsies from patients with PIN $(13,30)$. PC precursors provide a rationale for prophylactic RP. In patients with benign prostate or no biopsy, the benefits of RARP need to be justified. All patients in this series had LUTS, moderate prostate enlargement (mean volume $60 \mathrm{~cm}^{3}$ ) and a high PSA level (mean $=16 \mathrm{ng} / \mathrm{ml})$. In addition, $24 \%$ of our patients had experienced acute urinary retention.

All patients in this study underwent prophylactic RARP based on their willingness to undergo the procedure due to suspicion of PC, including abnormal PSA, PSA velocity, DRE, MRI and severe LUTS. Importantly, PC was finally diagnosed in 22 patients, including only two patients with clinically insignificant cancer $\leq 0.5 \mathrm{ml}$. The pathological stages in $\mathrm{T} 3 \mathrm{a} / \mathrm{T} 3 \mathrm{~b}$ were $27.3 \%$ and $4.5 \%$, and the positive surgical margin rate was $18.2 \%$ and $4.5 \%$ in those with angiolymphatic invasion. Gleason scores 7 and 8 were found in $45 \%$, suggesting further follow-up was needed. In other patients with final pathology reports of benign or ASAP after prophylactic RARP, there was no need to worry about developing PC.

This study has two main advantages. Firstly, it reflects real-world practice in patients with suspicion of PC whose lives were especially stressful and anxious. Although we have heard occasionally that other robotic surgeons had one or two patients with suspicion of PC who underwent RARP to treat the prostate and relieve the mental burden, those cases were not reported at international conferences. Prophylactic surgery is considered acceptable for 
pre-malignant lesions of the colon and breast, especially in patients with a family history of such cancer (13). We suggest that prophylactic RARP performed by experienced surgeons is also a viable option for patients with suspicion of PC. Moreover, the present series of RARP was performed by a single experienced surgeon who did not have surgical bias and maintained excellent outcomes. Prophylactic RARP, in our experience, is able to cure prostatic disease (malignancy, precursor lesion and benign), and to improve urinary symptoms and QOL simultaneously.

Limitations. This study has certain limitations, including that the data were collected prospectively but reviewed retrospectively, with no specific protocol and inclusion criteria. In spite of the best outcomes of prophylactic RARP, medico-legal problems still exist, and some countries may not permit the procedure due to legal issues. RARP can only be performed in high-volume centers and by very experienced surgeons. RARP should also not be applied for patients with keen desire to improve their sexual function and maintain normal ejaculation. Sexual function is not reported here due to the short evaluation period. In this series, 52 patients underwent bilateral NVB preservation, one unilateral NVB preservation, and two patients had no NVB preservation. The majority of patients underwent intrafascial NVB preservation in order to maximize erectile function recovery. Future studies should apply longer follow-up after RARP.

\section{Conclusion}

Prophylactic RARP with bilateral NVB preservation is safe for patients with suspicion of PC when performed by experienced surgeons. Postoperatively, RARP improves urinary function and QOL.

\section{Conflicts of Interest}

None declared.

\section{Acknowledgements}

The Authors wish to thank four mentors for helping to establish the robotic urology program, including A.K. Hemal, Wake Forest University (Winston-Salem, NC, USA); M.H. Kawachi, City of Hope, National Medical Center (Duarte, CA, USA); A.K. Tewari, Icahn School of Medicine at Mount Sinai (New York, NY, USA); and V.R. Patel, Global Robotics Institute, Florida Hospital (Orlando, FL, USA).

\section{References}

1 Mullins JK, Feng Z, Trock BJ, Epstein JI, Walsh PC and Loeb $\mathrm{S}$ : The impact of anatomical radical retropubic prostatectomy on cancer control: the 30-year anniversary. J Urol 188: 2219-2224, 2012 .
2 Kaul S and Menon M: Robotic radical prostatectomy: evolution from conventional to VIP. World J Urol 24: 152-160, 2006.

3 Tsui C, Klein R and Garabrant M: Minimally invasive surgery: national trends in adoption and future directions for hospital strategy. Surg Endosc 27: 2253-2257, 2013.

4 Patel VR, Abdul-Muhsin HM, Schatloff O, Coelho RF, Valero R, Ko YH, Sivaraman A, Palmer KJ and Chauhan S: Critical review of 'pentafecta' outcomes after robot-assisted laparoscopic prostatectomy in high-volume centres. BJU Int 108: 1007-1017, 2011.

5 Sood A, Jeong W, Peabody JO, Hemal AK and Menon M: Robot-assisted radical prostatectomy: inching toward gold standard. Urol Clin North Am 41: 473-484, 2014.

6 Diaz M, Peabody JO, Kapoor V, Sammon J, Rogers CG, Stricker H, Lane Z, Gupta N, Bhandari M and Menon M: Oncologic outcomes at 10 years following robotic radical prostatectomy. Eur Urol 67: 1168-1176, 2015.

7 Ou YC, Yang CK, Chang KS, Wang J, Hung SW, Tung MC, Tewari AK and Patel VR: The surgical learning curve for robotic-assisted laparoscopic radical prostatectomy: experience of a single surgeon with 500 cases in Taiwan. Asian J Androl 16: 728-734, 2014.

8 Coelho RF, Palmer KJ, Rocco B, Moniz RR, Chauhan S and Orvieto MA, Coughlin G and Patel VR: Early complication rates in a single-surgeon series of 2500 robotic-assisted radical prostatectomies: report applying a standardized grading system. Eur Urol 57: 945-952, 2010.

9 Brown CT, O'Flynn E, Van Der Meulen J, Newman S, Mundy $\mathrm{AR}$ and Emberton M: The fear of PC in men with lower urinary tract symptoms: Should symptomatic men be screened? BJU Int 91: 30-32, 2003.

10 Brindle LA, Oliver SE, Dedman D, Donovan JL, Neal DE, Hamdy FC, Lane JA and Peters TJ: Measuring the psychosocial impact of population-based prostate-specific antigen testing for prostate cancer in the UK. BJU Int 98: 777782, 2006.

11 Macefield RC, Metcalfe C, Lane JA, Donovan JL, Avery KN, Blazeby JM, Down L, Neal DE, Hamdy FC, Vedhara K and ProtecT Study Group: Impact of prostate cancer testing: an evaluation of the emotional consequences of a negative biopsy result. Br J Cancer 102: 1335-1340, 2010.

12 Brausi M, Castagnetti G, Dotti A, De Luca G, Olmi R and Cesinaro AM: Immediate radical prostatectomy in patients with atypical small acinar proliferation. Over treatment? J Urol 172: 906-908, 2004.

13 Woderich R, McLoughlin J and Deen S: Radical prostatectomy for high-grade prostatic intraepithelial neoplasia. Int Urol Nephrol 33: 649-650, 2001.

14 Pokorny M, Novara G, Geurts N, Dovey Z, De Groote R, Ploumidis A, Schatteman P, de Naeyer G and Mottrie A: Robotassisted simple prostatectomy for treatment of lower urinary tract symptoms secondary to benign prostatic enlargement: surgical technique and outcomes in a high-volume robotic centre. Eur Urol 68: 451-457, 2015.

15 Barry MJ, Fowler FJ Jr., O'Leary MP, Bruskewitz RC, Holtgrewe HL, Mebust WK, and Cockett AT: The American Urological Association symptom index for benign prostatic hyperplasia. The Measurement Committee of the American Urological Association. J Urol 148: 1549-1557, 1992. 
16 Witjes WP, de la Rosette JJ, Donovan JL, Peters TJ, Abrams P, Kay HE, Höfner K, Kinn AC and Walter S: The International Continence Society "Benign Prostatic Hyperplasia" Study: international differences in lower urinary tract symptoms and related bother. J Urol 157: 1295-1300, 1997.

17 Röthke M, Blondin D, Schlemmer HP and Franiel T: PI-RADS classification: structured reporting for MRI of the prostate. Röfo 185: 253-61, 2013.

18 Junker D, Schäfer G, Edlinger M, Kremser C, Bektic J, Horninger W, Jaschke W and Aigner F: Evaluation of the PIRADS scoring system for classifying mpMRI findings in men with suspicion of prostate cancer. Biomed Res Int 2013: 252939, 2013.

19 Ou YC, Yang CR, Wang J, Cheng CL and Patel VR: Comparison of robotic-assisted versus retropubic radical prostatectomy performed by a single surgeon. Anticancer Res 29: 1637-1642, 2009.

20 Ou YC, Yang CK, Wang J, Hung SW, Cheng CL, Tewari AK and Patel VR: The trifecta outcome in 300 consecutive cases of robotic-assisted laparoscopic radical prostatectomy according to D'Amico risk criteria. Eur J Surg Oncol 39: 107-113, 2013.

21 McNeal JE, Villers AA, Redwine EA, Freiha FS and Stamey TA: Histologic differentiation, cancer volume, and pelvic lymph node metastasis in adenocarcinoma of the prostate. Cancer 66: 1225$1233,1990$.

22 Nam RK, Saskin R, Lee Y, Liu Y, Law C, Klotz LH and Loblaw DA, Trachtenberg J, Stanimirovic A, Simor AE, Seth A, Urbach DR and Narod SA: Increasing hospital admission rates for urological complications after transrectal ultrasound guided prostate biopsy. J Urol 183: 963-968, 2010.

23 Autorino R, Zargar H, Mariano MB, Sanchez-Salas R, Sotelo RJ, Chlosta PL, Castillo O, Matei DV, Celia A, Koc G, Vora A, Aron M, Parsons JK, Pini G, Jensen JC, Sutherland D, Cathelineau X, Nuñez Bragayrac LA, Varkarakis IM, Amparore D, Ferro M, Gallo G, Volpe A, Vuruskan H, Bandi G, Hwang J, Nething J, Muruve N, Chopra S, Patel ND, Derweesh I, Champ Weeks D, Spier R, Kowalczyk K, Lynch J, Harbin A, Verghese M, Samavedi S, Molina WR, Dias E, Ahallal Y, Laydner H, Cherullo E, De Cobelli O, Thiel DD, Lagerkvist M, Haber GP, Kaouk J, Kim FJ, Lima E, Patel V, White W, Mottrie A and Porpiglia F: Perioperative Outcomes of Robotic and Laparoscopic Simple Prostatectomy: A European-American Multi-institutional Analysis. Eur Urol 68: 86-94, 2015.
24 Chen YK and Lin HC: Association between urologists' caseload volume and in-hospital mortality for transurethral resection of prostate: a nationwide population-based study. Urology 72: 329$335,2008$.

25 Ou YC, Yang CK, Chang KS, Wang J, Hung SW, Tung MC, Tewari AK and Patel VR: Prevention and management of complications during robotic-assisted laparoscopic radical prostatectomy following comprehensive planning: a large series involving a single surgeon. Anticancer Res 36: 1991-1998, 2016.

26 Salami SS, Ben-Levi E, Yaskiv O, Ryniker L, Turkbey B, Kavoussi LR, Villani R and Rastinehad AR: In patients with a previous negative prostate biopsy and a suspicious lesion on magnetic resonance imaging, is a 12-core biopsy still necessary in addition to a targeted biopsy? BJU Int 115: 562-570, 2015.

27 Loeb S, Roehl KA, Catalona WJ and Nadler RB: Is the utility of prostate-specific antigen velocity for prostate cancer detection affected by age? BJU Int 101: 817-821, 2008.

28 Loeb S, Metter EJ, Kan D, Roehl KA and Catalona WJ: Prostate-specific antigen velocity (PSAV) risk count improves the specificity of screening for clinically significant prostate cancer. BJU Int 109: 508-513, 2012.

29 Loeb S, Roehl KA, Yu X, Han M and Catalona WJ: Use of prostate-specific antigen velocity to follow up patients with isolated high-grade prostatic intraepithelial neoplasia on prostate biopsy. Urology 69: 108-112, 2007.

30 Montironi R, Mazzucchelli R, Lopez-Beltran A, Scarpelli M and Cheng L: Prostatic intraepithelial neoplasia: its morphological and molecular diagnosis and clinical significance. BJU Int 108 : 1394-1401, 2011.
Received June 22, 2016

Revised July 7, 2016

Accepted July 11, 2016 